UCRL-TR-209398

\title{
High Resolution Aerosol Modeling: Decadal Changes in Radiative Forcing.
}

D.J. Bergmann, C.C. Chuang, B. Govindasamy, P.J. Cameron-Smith, D.A. Rotman

February 2005

FY04 LDRD Final Report 


\section{Disclaimer}

This document was prepared as an account of work sponsored by an agency of the United States Government. Neither the United States Government nor the University of California nor any of their employees, makes any warranty, express or implied, or assumes any legal liability or responsibility for the accuracy, completeness, or usefulness of any information, apparatus, product, or process disclosed, or represents that its use would not infringe privately owned rights. Reference herein to any specific commercial product, process, or service by trade name, trademark, manufacturer, or otherwise, does not necessarily constitute or imply its endorsement, recommendation, or favoring by the United States Government or the University of California. The views and opinions of authors expressed herein do not necessarily state or reflect those of the United States Government or the University of California, and shall not be used for advertising or product endorsement purposes.

\section{Auspices Statement}

This work was performed under the auspices of the $U$. S. Department of Energy (DOE) by the University of California, Lawrence Livermore National Laboratory (LLNL) under Contract No. W-7405-Eng-48. The project (04-ERD-089) was funded by the Laboratory Directed Research and Development Program at LLNL. 


\title{
FY04 LDRD Final Report High Resolution Aerosol Modeling: Decadal Changes in Radiative Forcing LDRD Project Tracking Code: 04-ERD-089 Daniel Bergmann, Principal Investigator
}

\begin{abstract}
The Atmospheric Science Division of LLNL has performed high-resolution calculations of direct sulfate forcing using a DOE - provided computer resource at NERSC. We integrated our global chemistry-aerosol model (IMPACT) with the LLNL high-resolution global climate model (horizontal resolution as high as $100 \mathrm{~km}$ ) to examine the temporal evolution of sulfate forcing since 1950 . We note that all previous assessments of sulfate forcing reported in IPCC (2001) were based on global models with coarse spatial resolutions ( $300 \mathrm{~km}$ or even coarser). However, the short lifetime of aerosols ( $\sim$ days) results in large spatial and temporal variations of radiative forcing by sulfate. As a result, global climate models with coarse resolutions do not accurately simulate sulfate forcing on regional scales. It requires much finer spatial resolutions in order to address the effects of regional anthropogenic $\mathrm{SO}_{2}$ emissions on the global atmosphere as well as the effects of longrange transport of sulfate aerosols on the regional climate forcing. By taking advantage of the tera-scale computer resources at NERSC, we simulated the historic direct sulfate forcing at much finer spatial resolutions than ever attempted before. Furthermore, we performed high-resolution chemistry simulations and saved monthly averaged oxidant fields, which will be used in subsequent simulations of sulfate aerosol formation and their radiative impact.
\end{abstract}

\section{Introduction/Background}

Atmospheric aerosols along with greenhouse gases play important roles in mediating the radiation balance of the Earth-atmosphere system. In some regions sulfur and other aerosol emissions from fossil fuel combustion and biomass burning may be as important to climate change as greenhouse gases (Taylor and Penner; 1994; Chuang et al., 1997; Hansen et al., 1997, 1998; Ramanathan et al., 2001). Atmospheric aerosols have a tropospheric lifetime of about a week, vary geographically and seasonally, and scatter or absorb solar radiation depending on the aerosol composition. Greenhouse gases, including the well-mixed trace gases $\left(\mathrm{CO}_{2}, \mathrm{CH}_{4}, \mathrm{~N}_{2} \mathrm{O}\right.$ and halocarbons), ozone and non-methane hydrocarbons, primarily affect the long wave radiation and warm the earth. In contrast, the scattering of sunlight by aerosols (i.e. direct effects) tends to cool the Earth and tend to 
counteract the warming effects of greenhouse gases. The atmospheric concentrations of both aerosols and greenhouse gases have increased over the past century and, because of their effects on shortwave and long wave radiation (which are partially offsetting), have presumably upset to some degree the thermal equilibrium of the climate system.

While satellite measurements and field studies provide vital information to document the global and regional climate impacts by aerosols and greenhouse gases, accurate climate model simulations are likely the best approach to quantify the radiative forcing as well as to identify and analyze the climate response. Nevertheless, a major factor limiting the quality and usefulness of global climate models is their coarse spatial resolutions. Global climate models are typically run at resolutions of $\sim 300 \mathrm{~km}$, or even coarser, that do not allow adequate representation of topographic features which strongly influence the surface temperature and precipitation. As a result, global climate models with coarse resolutions do not accurately simulate climate on regional scales. An important consequence of this inability is that coarse global climate model results cannot be used as the basis for assessments of potential anthropogenic influence on regional climate change. It requires much finer spatial resolutions in order to address the effects of regional pollution on the global atmosphere as well as the effects of long-range transport of aerosols and greenhouse gases (mainly ozone) on the regional climate. This has not been attempted previously because the computational demands have been prohibitive.

\section{Research Activities}

Over the six-month period covered by this proposal we used a special allocation of computing time provided by the DOE Office of Science INCITE (Innovative and Novel Computational Impact on Theory and Experiment) program. Three distinct computer calculations were performed:

A high-resolution climate run using the LLNL version of the CAM3 NCAR climate model was completed. The purpose of this simulation was to obtain meteorological output at $1^{\circ}$ (latitude) by $1.25^{\circ}$ (longitude) horizontal resolution and 3 hour temporal resolution that will drove the LLNL IMPACT (Rotman et al. 2004) chemistry-aerosol model. Prior to running the CAM3 model, modifications were made so that the necessary fields would be written. After completing the simulations, the

climate results were examined using PCMDI tools to ensure a high quality and stabilized climate simulation.

Five different 15 month long ( 3 month spin up, plus one year) IMPACT simulations at $1^{\circ}$ by $1.25^{\circ}$ horizontal resolution using aerosol emissions for 1950 's, 1960 's, 1970's 1980's and 1990's were completed Since the lifetime of aerosols is a week or so, year long simulations were adequate to examine seasonality in aerosol 
distributions. We then analyzed the radiative forcing of aerosols, paying particular attention to regional attributes of aerosol forcing and how those regional attributes vary as a function of decade.

A single 15 month full ozone chemistry calculation was then completed which produced high-resolution oxidant fields that can be used in future IMPACT sulfur chemistry calculations. The availability of these fields will enable LLNL to quickly run high-resolution parameter studies concerning sulfur chemistry and analyze the resulting changes to the Earth's radiation budget. This ability puts us in a much stronger position to compete for future funding in this area.

\section{Results/Technical Outcome}

The CAM3 climate simulation calculation produced high-resolution meteorological fields, which are required to drive the IMPACT atmospheric chemistry model. High resolution is only important when key variables have steep gradients. An example of this is shown in Figure 1 . Specific humidity ( $\mathrm{gm} \mathrm{H} 20 / \mathrm{kg}$ air) is plotted at the surface on September 1st. This is a key variable required for accurate predictions of sulfate aerosol distributions. Note the steep gradients and fine structure in the picture.

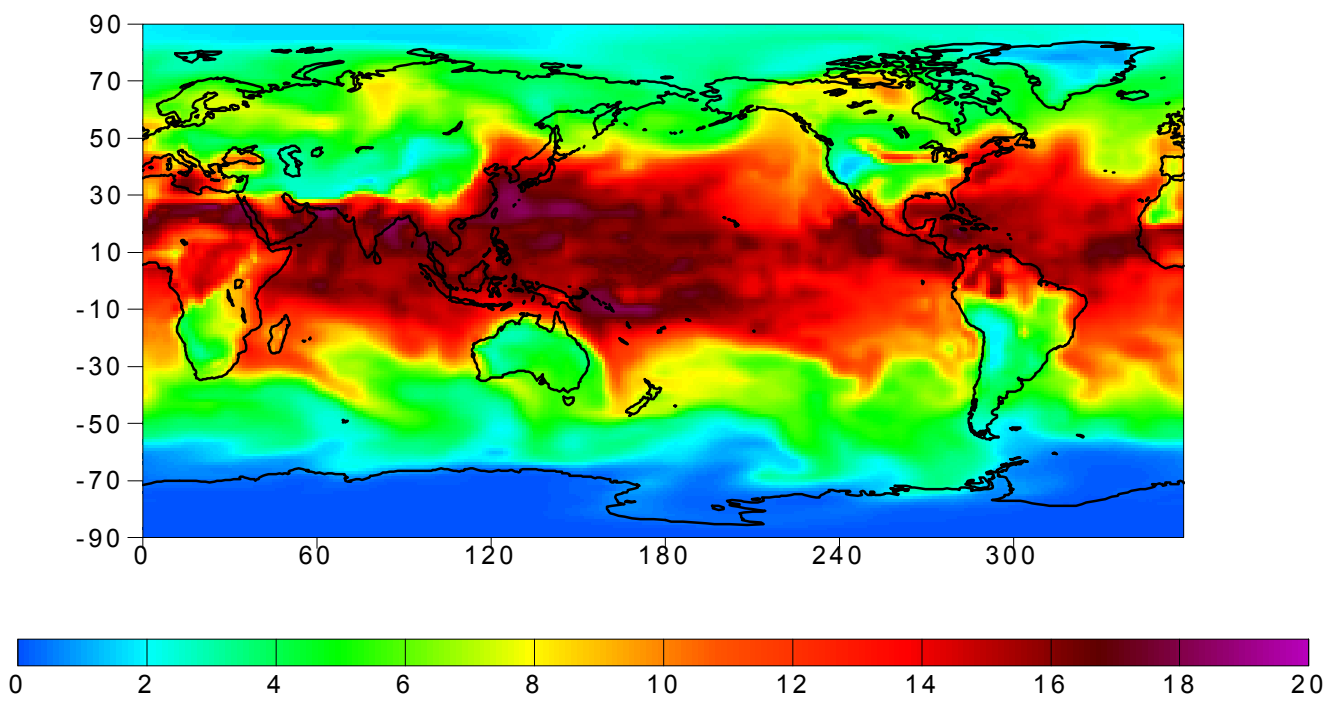

Figure 1: Sample output from the CAM3 model simulations. Specific humidity $(\mathrm{g} / \mathrm{kg})$ at the surface on September 1. 
This high-resolution climate data was then used to drive 5 different IMPACT sulfur chemistry simulations representing the final five decades of the twentieth century. By applying the monthly averages of $\mathrm{O} 3, \mathrm{OH}, \mathrm{HO} 2$, and $\mathrm{NO} 3$ that were regridded from previous IMPACT simulations at coarse horizontal resolution, sulfate are formed through both gas phase (with $\mathrm{OH}$ ) and aqueous phase (with $\mathrm{H} 2 \mathrm{O} 2$ and $\mathrm{O} 3$ ) oxidation from SO2 and DMS. We recognize that these monthly averages may not be consistent with the high-resolution meteorology used to drive the IMPACT. Nevertheless, the merit of this task is to provide the first attempt to simulate highresolution aerosol forcing.

To assess the decadal changes of direct sulfate forcing, we adapted a historic emissions inventory of SO2 from fossil fuels for the years 1950 through 1994 with global emissions varying from 30.2 to $70.4 \mathrm{TgS}$ (Dignon, 1998). This historic emissions inventory not only presents a significant global increase in the emission level of SO2 but also demonstrates an important regional variation. How these temporal and regional variations affect the geographical distribution of direct sulfate forcing as well as its subsequent effect on climate should be an issue of interest. It is noted, in 1950, North America contributed $41 \%$ of the global fossil fuel SO2 emissions, a fraction which has decreased to $15 \%$ in the mid-1990s. This drop has resulted primarily from the conservation and pollution policies imposed. Similar tendency is also observed in Europe, for which the percentage decreases from $34 \%$ to $17 \%$. Asia, on the other hand, has had a 6 -fold increase in its fractional contribution climbing from $7 \%$ in 1950 to $44 \%$ in the mid-1990s.

The radiative affects of the anthropogenic sulfate aerosols were then analyzed for each of the simulations. These results are shown in figure 2 . When comparing 1950 (top left panel) to 1990 (bottom right panel), note the increased regional cooling effects in central Asia, India, and particularly in eastern Asia. The globally averaged direct forcing $\left(\mathrm{W} / \mathrm{m}^{2}\right)$ is calculated to increase between 1950 and 1990 from -0.18 (1950), -0.34 (1970), -0.36 (1980), to -0.43 (1990).

High-resolution simulations can show much more detailed regional features. For example, the simulated maximum forcing for year 1990 is located just off the coast of East Asia instead of over the continent as compared to our previous calculations (Chuang et al., 1999). This feature demonstrates that low surface albedo favors the cooling from aerosol scattering. 

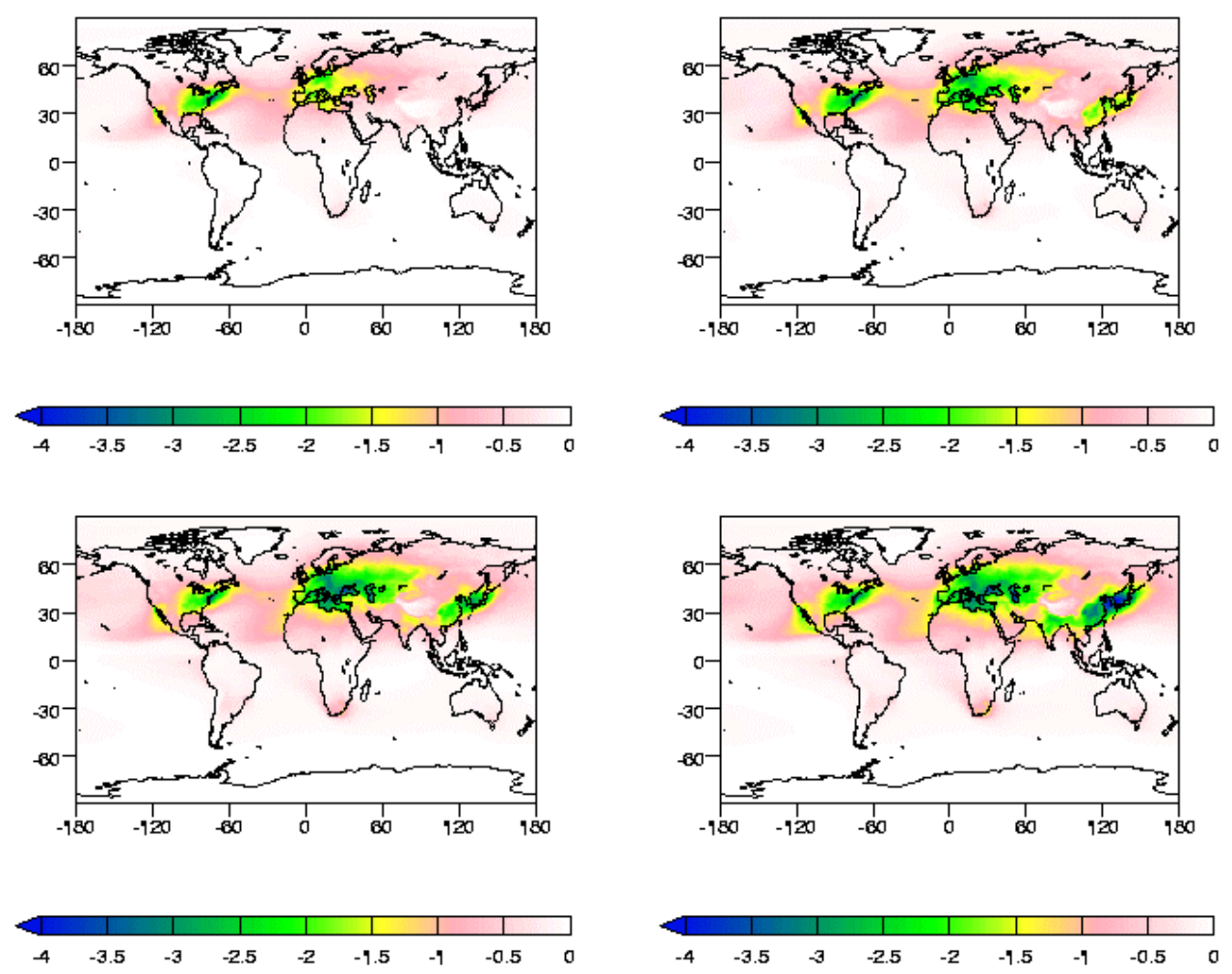

Figure 2: IMPACT model predicted effects on shortwave radiation (watts $/ \mathrm{m} 2)$ due to anthropogenic sulfate aerosols in four different decades: 1950's (top left), 1970's (top right), 1980's (bottom left), and 1990's (bottom right).

Finally, a full chemistry simulation was completed which provides the IMPACT modeling team with high resolution oxidant fields which can be used to run fast parameter studies of sulfur chemistry and its impact on the global radiation budget. A sample of the fields generated is shown in figure 3. This shows modeled ozone at the surface during the month of July. Even though this is a monthly averaged field, note the steep horizontal gradients in ozone. Ozone is an important trace species involved in the production of sulfate aerosols from SO2 gas. 


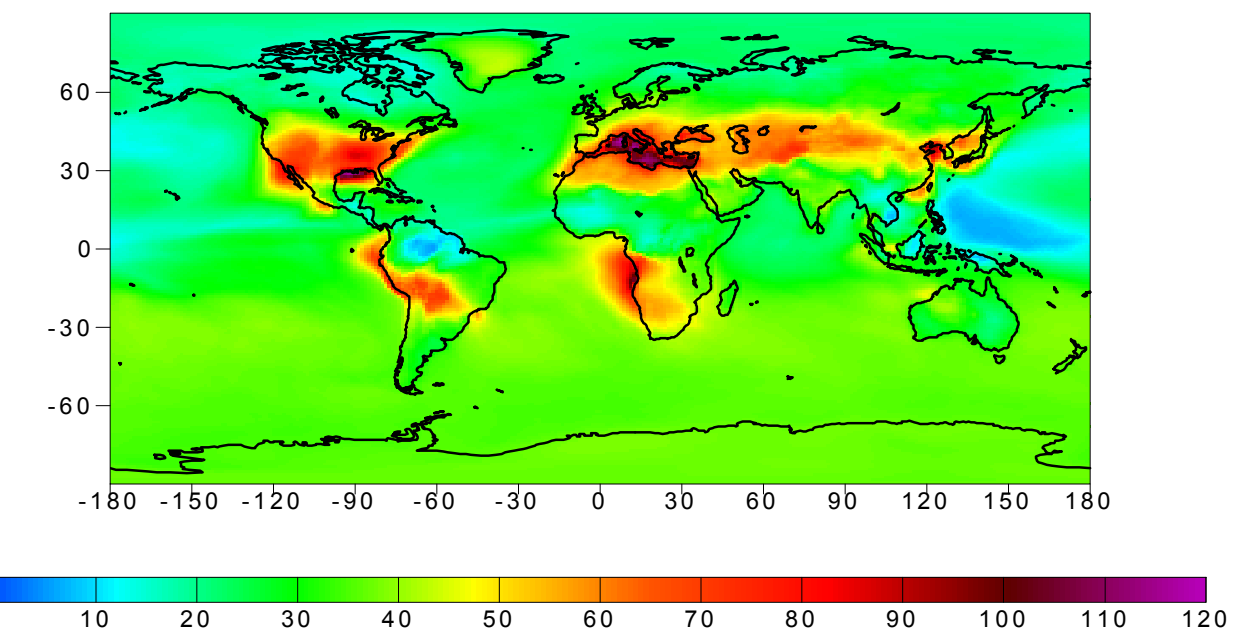

Figure 3: Surface ozone (ppbv) in July as simulated by IMPACT using the $1 \times 1.25$ degree resolution CAM3 model.

\section{Exit Plan}

The DOE implemented an "Aerosol Initiative", in the ASP (Atmospheric Sciences Program) with a funding date of Nov. 1, 2004. Based on the IMPACT chemistry/aerosol model and its use within this LDRD to simulate regional aspects of aerosols in a global domain, we were successful and received funding through ASP (Atherton 2004). Accomplishing this LDRD's deliverables enabled us to successfully compete and receive funding for this DOE call and demonstrate a leadership position for LLNL in this new initiative as well as the aerosol science community.

\section{Summary}

Using an award of computer time from DOE, three sets of high resolution simulations were completed. They included a climate simulation, decadal sulfur simulations for the final 5 decades of the last century, and a full ozone chemistry simulation. These results positioned us to compete successfully for DOE funds and results of the chemistry simulations will be indispensable for future sulfate aerosol and radiative forcing calculations. 


\section{References}

Atherton, C.S., D.J. Bergmann, P.S. Connell, 2004: Atmospheric Formation, Transformation, and Radiative Forcing of Secondary Organic Aerosols. UCRLPROP-204592.

Bergmann, D.J., C.C. Chuang, D.A. Rotman, 2004: LLNL Scientists use NERSC to Advance Global Aerosol Simulations, NERSC News August 1, 2004, pp. 1,3 UCRLJRNL-207209

Chuang, C.C., J.E. Penner, K.E. Taylor, A.S. Grossman, and J.J. Walton, 1997: An assessment of the radiative effects of anthropogenic sulfate, J. Geophys. Res., 102, 3761-3778.

Chuang, C.C., D. Bergman, J. Dignon, and P. Connell, 2002: Final Report for LDRD Project "A New Era of Research in Aerosol/Cloud/Climate Interactions at LLNL", LDRD-UCRL-ID-146980.

Chuang, C.C., K.E. Grant, and J.E. Dignon, 1999: Modeling the past and future direct sulfate forcing from fossil fuel combustion, UCRL-JC-13357.

Dignon, J, 1999: Historic $\mathrm{SO}_{2}$ emissions from fossil fuel combustion - Potential for climate change, UCRL-JC-130247.

Duffy, P.B., B. Govindasamy, J. Milovich, K. Taylor, M. Wehner, A. Lamont, and S. Thompson, High resolution simulations of global climate, Part 1: Present climate, submitted to Climate Dynamics.

Grant, K.E., A.S. Grossman, and R.L. Tarp, 1997: Methods and models used to parameterize the infrared absorption of methane and nitrous oxide for calculations within the LLNL/UCLA climate model, UCRL-ID-129290.

Grant, K.E., C.C. Chuang, A.S. Grossman, and J.E. Penner, 1999: Modeling the spectral optical properties of ammonium sulfate and biomass burning aerosols: Parameterization of relative humidity effects and model results, Atmos. Environ., 33, 2603-2620.

Hansen, J.E., M. Sato, and R. Ruedy, 1997: Radiative forcing and climate response, J. Geophys. Res., 102, 6831-6864.

Hansen, J.E., M. Sato, A. Lacis, R. Ruedy, I. Tegen, and E. Matthews, 1998: Climate forcings in the industrial era, Proc. Natl. Acad. Sci., 95, 12,753-12,758.

Ramanathan, V, P.J. Crutzen, J.T. Kiehl, and D. Rosenfeld, 2001: Aerosols, climate, and the hydrological cycle, Science, 294, 2119-2124.

Rotman, D.A., C. Atherton, D. Bergmann, C. Chuang, P. Connell, J. Dignon, D. Kinnison, J. Tannahill, 2004: IMPACT, the LLNL 3-D global atmospheric chemical transport model for the combined troposphere and stratosphere: Model description and analysis of ozone and other trace gases, J. Geophys. Res 109 doi: 10.1029/2002JD003155.

Taylor, K.E., and J.E. Penner, 1994: Response of the climate system to atmospheric aerosols and greenhouse gases, Nature, 369, 734-737. 